\title{
Verleihung Förderpreis der Sektion Kopf-Hals 2020
}

Bei dem Treffen der Sektion Kopf-Hals der DEGUM am Ende Juli wurde der diesjährige Förderpreis der DEGUM für junge Nachwuchswissenschaftler mit dem Schwerpunkt Kopf-Hals-Sonografie verliehen. Der Preis ging an PD Dr. Miguel Goncalves aus Erlangen. Dr. Goncalves hatte sich im Rahmen seiner akademischen Laufbahn intensiv mit der Ultraschalldiagnostik der Speicheldrüsen und besonders der entzündlichen Veränderungen befasst. In mehreren Publikationen konnte besonders der Einsatz der Sonografie mit der Speichelgangendoskopie komplementär un- tersucht werden. Als Ergebnis konnte durch die Kombination beider bzw. minimal-invasiver Verfahren nachgewiesen werden, dass eine mehrheitlich drüsenerhaltende Therapie bei obstruktiven Erkrankungen möglich ist. Alle eingereichten Bewerbungen zeigten ein ansprechendes sonografisches Interesse junger Wissenschaftler an sonografischen Verfahren im Kopf-Hals-Bereich. Auch für 2021 wird der Preis in der zweiten Jahreshälfte ausgelobt. Bewerber können sich mit entsprechenden Beiträgen an die Geschäftsstelle der DEGUM wenden.

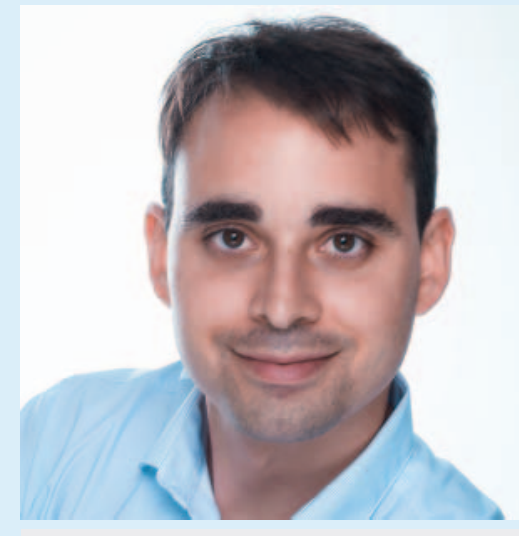

Preisträger PD Dr. Miguel Goncalves 